\title{
Transformation of Escherichia coli JM109 using pUC19 by the Yoshida effect
}

\author{
G.P. Mendes ${ }^{\mathrm{a}, \mathrm{b}}$, P.S. Vieira ${ }^{\mathrm{a}}$, S. Lanceros-Méndez ${ }^{\mathrm{b}}$, L.D. Kluskens ${ }^{\mathrm{a}, *}$, M. Mota ${ }^{\mathrm{a}}$ \\ a CEB - Centro de Engenharia Biológica, Universidade do Minho, 4710-057 Braga, Portugal \\ b Centro/Departamento de Física, Universidade do Minho, 4710-057 Braga, Portugal
}

\section{A R T I C L E I N F O}

\section{Article history:}

Received 25 April 2015

Accepted 8 May 2015

Available online 9 May 2015

\section{Keywords:}

Yoshida effect

Transformation

Sepiolite

E. coli

\begin{abstract}
A B S T R A C T
Transformation of non-competent Escherichia coli JM109 was accomplished using pUC19 as donor plasmid and sepiolite as the acicular material to promote cell piercing via application of friction with a polystyrene stick or a magnetic bar on the surface of a hydrogel containing agar. An automatic spreading setup was built with a conventional stirring plate and compared to manual spreading. Several parameters were optimized, namely, the agar content of the hydrogel ( $2 \%)$, concentration of cells $\left(\mathrm{OD}=1.3\right.$ corresponding to $1.4 \times 10^{9}$ bacterial cells/ $\mathrm{mL}$ ), concentration of sepiolite $(0.01 \%)$, manual versus mechanical spreading (automatic spreading more consistent) and spreading time (30 s). Efficiency values up to $4.1 \times 10^{4} \mathrm{CFU} / \mu \mathrm{g}$ pUC19 were obtained. The method proved to be suitable for a rapid and low cost transformation of non-competent E. coli JM109, where higher values of efficiency do not need to be attained.
\end{abstract}

C 2015 Published by Elsevier B.V.

\section{Introduction}

Since 2001 Yoshida and co-workers published a few exciting papers describing a new transformation method with large potential (Yoshida and Ide, 2008; Yoshida and Saeki, 2004a, 2004b; Yoshida and Sato, 2009; Yoshida, 2001, 2007; Yoshida et al., 2002, 2004). This method, coined as tribos transformation is simpler, faster and more costeffective than electroporation and chemotransformation (Tan et al., 2010). It is based on the use of a colloidal solution containing mineral nano-needles mixed with non-competent bacteria and DNA to directly plate on agar/lysogeny broth (LB) Petri dishes, containing selection markers, using friction forces only. The sliding friction forces, due to spreading of the colloidal solution on the surface of the selective agar plate results in penetration of the bacterial cells by the nano-needles delivering DNA to the interior of the cell. This phenomenon has been termed Yoshida effect in honor of its inventor. However, little notice has been paid to this method probably because $(i)$ Yoshida and co-workers mostly used as a source of nano-needles the asbestos chrysotile which is known to have hazardous consequences and its manipulation presents a health risk (Suzuki et al., 1972); (ii) in some papers the authors refer to the use of a sophisticated homemade apparatus to spread the colloidal solution on agar plates which may have discouraged some potential users or (iii) the results proved to be unreliable and difficult to replicate.

\footnotetext{
* Corresponding author.

E-mail address: kluskens@deb.uminho.pt (L.D. Kluskens).
}

In the present work we assessed the potential of this method and confirmed that it can be improved to achieve a more reliable and harmless application. First, sepiolite was used instead of chrysotile, due to the mentioned health risks associated with the use of chrysotile. Sepiolite is a clay mineral, a complex magnesium silicate, which can be present in fibrous, fine-particulate, and solid forms. Sepiolite has been mentioned previously by Yoshida et al. as a source of nano-needles (Yoshida and Sato, 2009) and its mineral deposits are exploited mainly for the production of absorbents such as pet litter or used in construction as lime mortar. The type used in our essays is a fine-particulate hydrous magnesium silicate of Spanish origin with formula $\mathrm{H}_{4} \mathrm{Mg}_{2} \mathrm{Si}_{3} \mathrm{O}_{10}$. Due to its structure of very thin crystals it is also used as asbestos substitute and the biological effects of sepiolite fibers have been shown to be mild as compared with those of asbestos (Landrigan et al., 1999). Spanish sepiolite is known to have no carcinogenic potential and a lower biological activity compared to sepiolite from Finland and China, likely due to minor fractions of fibers with a length above $5 \mu \mathrm{m}$ and due to the low biodurability of Spanish sepiolite (Bellmann et al., 1997). Transformation with sepiolite has been published only a few times (Mitsudome et al., 2014; Rodríguez-Beltrán et al., 2012, 2013; Tan et al., 2010; Wilharm et al., 2010). Other minerals such as kaolinite and bentonite have been tried but induced undesirable mutations on the host bacterium (Yoshida et al., 2004) and do not promote plasmid transport into E. coli cells (Yoshida and Takebe, 2006). Sepiolite is thus an inexpensive substance not presenting health risks for humans and seems the most suitable choice for a widespread use of tribos transformation on bacteria. The utilization of sepiolite and the optimization of the conditions to 
exploit its potential as a transformation method are the subjects of this work.

\section{Materials and methods}

Sepiolite mined in Spain with a mean fiber length of $2 \mu \mathrm{m}$ and a mean diameter of $20 \mathrm{~nm}$ was purchased from Kremer Pigmente GmbH \& Co. KG, (Germany cat. no. 58945) and used for our transformation studies (Wilharm et al., 2010; Yoshida and Sato, 2009). NaCl was purchased from Panreac (Spain), isopropyl $\beta$-D-1-thiogalactopyranoside (IPTG) and 5-bromo-4-chloro-3-indolyl- $\beta$-D-galactopyranoside (X-gal) were purchased from Nzytech (Portugal), and ampicillin was purchased from Fisher Scientific (USA). LB and agar were purchased from Liofilchem Diagnostic (Italy). Instead of using a sophisticated homemade apparatus we used a conventional stirrer plate and a bar magnet to spread the colloidal solution on top of agar plates, and compared our results with manual spreading of the colloidal solution with a stir stick (Fig. 1a, b). Experiments were carried out in a laminar flow cabinet to avoid contaminations. We used $50 \mathrm{ng}$ of plasmid per Petri dish to obtain hundreds of transformants contrary to $1 \mathrm{ng}$ to 0.1 ng per Petri dish that can be used by the other methods (Huff et al., 1990; Prentice, 1992). The amount of DNA generally used in heat shock or electroporation experiments is much lower than the amount used with our sepiolite essays, giving rise to higher efficiencies of transformation. A 4\% sepiolite was autoclaved in distilled water containing $150 \mathrm{mM} \mathrm{NaCl}$. Dilutions of this suspension were made in $150 \mathrm{mM} \mathrm{NaCl}$ to obtain $1 \%, 0.1 \%$ and $0.01 \%$ sepiolite for further use. We optimized various parameters in our experiments to obtain the maximum efficiency expressed in colony forming units per $\mu \mathrm{g}$ plasmid (CFU/ $\mu$ g plasmid). Petri dishes were prepared by autoclaving LB and agar in distilled water and after cooling to about $45^{\circ} \mathrm{C}$ IPTG, X-gal and ampicillin was added to final concentrations of $1 \mathrm{mM}, 40 \mu \mathrm{g} / \mathrm{mL}$ and $100 \mu \mathrm{g} / \mathrm{mL}$ respectively. The amount of agar/LB used per Petri dish was $15 \mathrm{~mL}$. In a typical experiment a 50 -fold dilution of an overnight

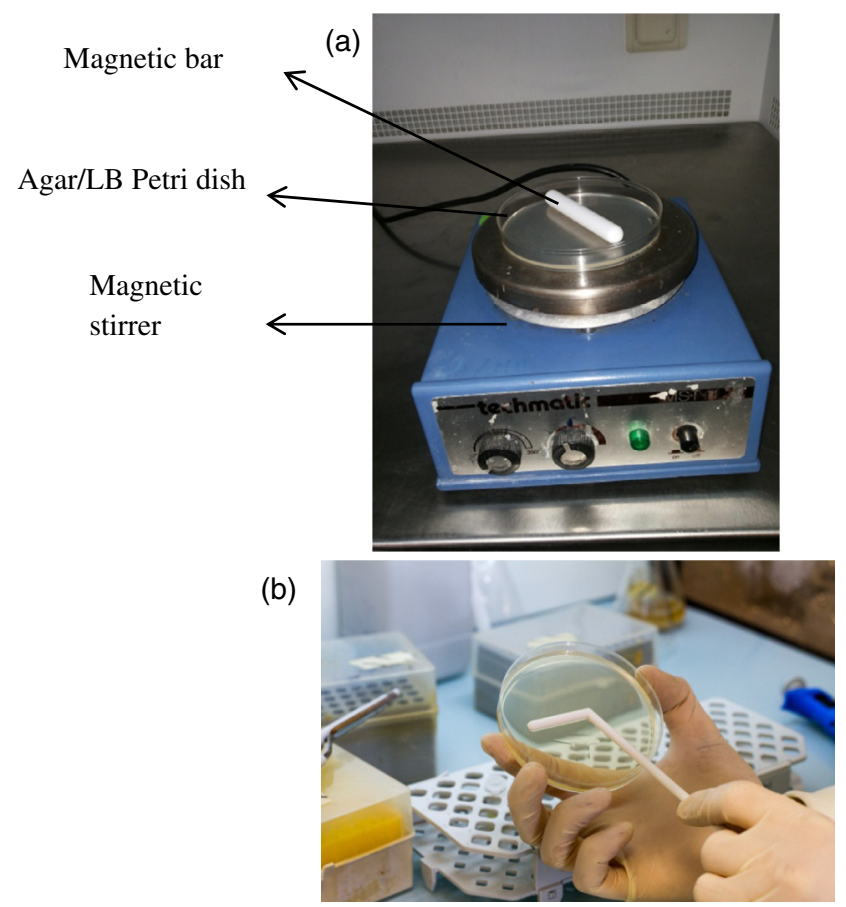

Fig. 1. Set-up of the applied spreading methods. (a) Automatic spreading using a magnetic bar and a stirrer to spread the microorganisms with the DNA/nano-needle mixture. (b) Manual procedure for spreading the colloidal solution of microorganisms with the DNA/nano-needle mixture. culture (200 rpm, $37^{\circ} \mathrm{C}$ ) of Escherichia coli JM109 was used. Following the growth until a certain optical density, $500 \mu \mathrm{L}$ of $E$. coli JM109 per Petri dish was centrifuged at $16162 \times g$ for 3 min and the supernatant was decanted. Sepiolite dispersion is blended with plasmid DNA (about 50 ng plasmid per Petri dish) and the pellet of E. coli was resuspended in the pUC19-sepiolite dispersion by vortexing for $1 \mathrm{~min}$. Prior to spreading the E. coli-pUC19-sepiolite dispersion onto the agar, Petri dishes were dried for $20 \mathrm{~min}$ to remove moisture. One hundred microliters of this dispersion was then pipetted on top of agar/LB Petri dishes and spread manually using a polystyrene stick or using a magnetic Teflon coated bar on a magnetic stirrer until the E. coli-pUC19-sepiolite suspension was completely absorbed into the agar/LB Petri dish. Plates were incubated overnight at $37^{\circ} \mathrm{C}$. The following day, the amount of blue transformants was quantified using an Interscience Scan 300 automatic colony counter and efficiency of transformation was determined. Five replicas of each experiment were performed and the highest and lowest counts of colonies were eliminated to diminish the standard deviation observed, so the graphs presented are taken from values in triplicate. We also varied the concentration of cells by dilution or concentrating from a certain optical density to study the effect of physiological conditions on transformation efficiency. Plasmid DNA extraction was accomplished with a Nucleospin (NoLid) kit from MachereyNagel (Germany), and submitted to analysis by agarose gel electrophoresis (1\%).

\subsection{Statistical analysis}

To assess statistical differences among different samples, a one-way ANOVA test was used. For determining differences among means, a Tukey HDS test was performed when required. Differences were considered significant for P value $\leq 0.05 .{ }^{*} 0.05 \geq \mathrm{P}>0.01 ;{ }^{* *} 0.01 \geq \mathrm{P}>0.001$; ${ }^{* * *} \mathrm{P} \leq 0.001$. All tests were performed using GraphPad Prism analysis package.

\section{Results}

\subsection{Transformation of E. coli JM109 on Petri dishes}

Transformation efficiency depends on the agar concentration.

To have an idea of the quantity of plasmid needed to achieve a countable amount of transformants (+/-200-400) per Petri dish a transformation experiment was conducted with increasing plasmid concentrations (See Fig. 2). Based on these results it was decided to use an amount of $50 \mathrm{ng}$ of plasmid in the following experiments.

We first varied the agar concentration on Petri dishes which involves different stiffness of the hydrogel and consequently different frictional force during the spreading of the E. coli-pUC19-sepiolite suspension. All Petri dishes were prepared with $2 \%$ LB and a varying agar \% (1-4\%). The optimal transformation efficiency was obtained with $2 \%$ Agar (Fig. 3), however transformants were obtained for all agar concentrations used. The spreading was manually performed during $1 \mathrm{~min}$. Sepiolite percentage used was $0.01 \%$ and the optical density of cells used was $1.2\left(\mathrm{OD}_{600}=1.2\right)$.

\subsection{Automatic spreading is more reliable than manual operation}

The transformation efficiency obtained was comparable for manual spreading and automatic spreading for sepiolite concentrations of $0.01 \%$ and $1 \%$ (Fig. 4 ). For $0.1 \%$ sepiolite, automatic spreading produced more colonies than manual spreading (average of $2.1 \times 10^{4} \mathrm{CFU} / \mu \mathrm{g}$ pUC19 versus $1.40 \times 10^{4} \mathrm{CFU} / \mu \mathrm{g}$ pUC19). The $\mathrm{OD}_{600}$ used was 1.3 and the spreading time was $30 \mathrm{~s}$ in both cases. The maximum average efficiency obtained was $3.0 \times 10^{4}$ for $0.01 \%$ sepiolite for both manual and automatic spreading. 


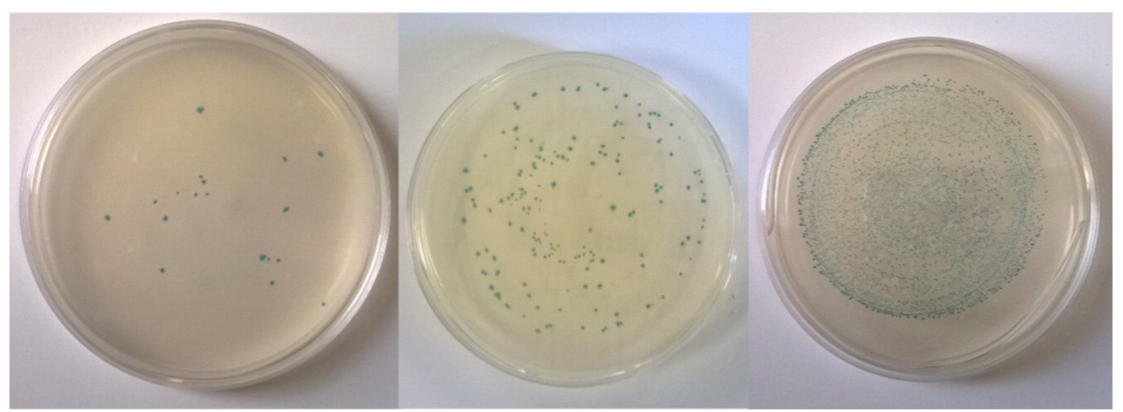

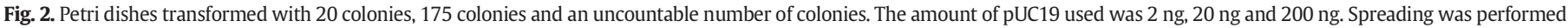
automatically using a Teflon coated magnetic bar.

\subsection{Effect of optical density on transformation efficiency}

The optical density which resulted in the maximum efficiency of transformation was shown to be $\mathrm{OD}_{600}=1.3$. Fig. 5 shows that the maximum transformation efficiency was obtained for a sepiolite concentration of $0.01 \%$ for all optical densities tested besides OD $=1.5$ for which the efficiency with $0.01 \%$ sepiolite was similar to sepiolite $0.1 \%$. The spreading time used was $30 \mathrm{~s}$ for all optical densities tested under this essay. The maximum efficiency obtained was $4.1 \times 10^{4} \mathrm{CFU} / \mu \mathrm{g}$ pUC19 for $0.01 \%$ sepiolite at $\mathrm{OD}_{600}=1.3$.

Fig. 6 shows the results of dilutions or concentrations that were made to ensure that all Petri dishes received the same number of cells. The maximum efficiency obtained was at $\mathrm{OD}_{600}=1.2$ from initial $\mathrm{OD}_{600}$ of 1.3 (efficiency $=2.0 \times 10^{4} \mathrm{CFU} / \mathrm{\mu g}$ pUC19). The essay was performed with $0.01 \%$ sepiolite in all conditions tested and the spreading time was also $30 \mathrm{~s}$.

\subsection{Automatic and manual spreading versus spreading time}

We tested various spreading times for automatic and manual spreading $(15,30,60$ and $120 \mathrm{~s})$. These results show that the spreading time did not produce a significant difference in efficiency between $30 \mathrm{~s}$ and $60 \mathrm{~s}$ for automatic spreading but it did display a significant difference in efficiency for manual spreading during the same times (Fig. 7). The best time for spreading manually is $30 \mathrm{~s}$.

\subsection{Viability study of E. coli JM109 vs sepiolite concentration}

We studied the influence of the concentration of sepiolite on cell death by diluting cells $90 \times$ from an overnight culture with an initial

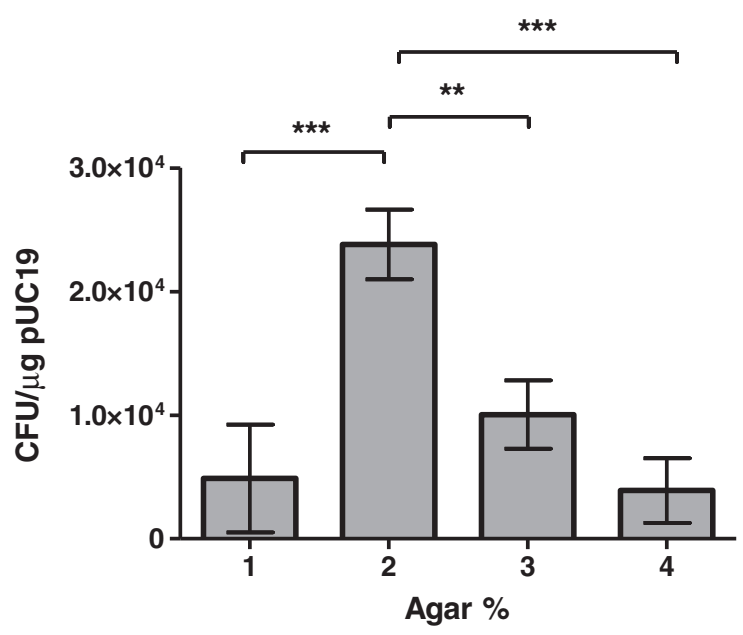

Fig. 3. Transformation efficiency versus agar concentration.
$\mathrm{OD}_{600}=1.3$. The spreading was manually performed during $30 \mathrm{~s}$. The Petri dishes (LB/Agar 2\%) did not contain any marker and no plasmid was used. As can be observed in Fig. 8, there was a significant decrease in the number of colonies for $0.1 \%$ and $1 \%$ sepiolite when compared to $0.01 \%$ sepiolite.

\subsection{Confirmation of pUC19/E. coli JM109 transformation by agarose gel} electrophoresis

Four colonies were randomly picked and grown in LB with $100 \mu \mathrm{g} / \mathrm{mL}$ ampicillin overnight. The pUC19 plasmid was extracted and an agarose gel was run to confirm the size of the plasmid (Fig. 9). pUC19 has 2686 bps and was linearized by EcoRV and HindIII. As can be seen in Fig. 9, the digested plasmids migrated to just below the $3 \mathrm{~kb}$ band of the DNA marker ladder.

\section{Discussion}

The maximum transformation efficiency obtained at $2 \%$ agar with a spreading time duration of $1 \mathrm{~min}$, sepiolite percentage of $0.01 \%$ and an optical density of cells of $1.2\left(\mathrm{OD}_{600}=1.2\right)$ was $2.7 \times 10^{4} \mathrm{CFU} / \mu \mathrm{g}$ pUC19 (Fig. 3). This efficiency is lower than the one obtained by Yoshida and colleagues using chitin nano-whiskers $\left(2.6 \times 10^{5} \mathrm{CFU} / \mathrm{pUC18}\right)$ with JM109 cells on 2.5\% agar hydrogels (Mera et al., 2011). Wilharm et al. also using sepiolite obtained a higher efficiency for pUC19 and E coli TOP 10 cells $\left(2 \times 10^{6} \mathrm{CFU} / \mu \mathrm{g}\right.$ pUC19) (Wilharm et al., 2010). The differences might be attributed to the different strain used in the latter case and to the smaller size of nano-needles in the case of chitin $(7 \times 7 \times 150 \mathrm{~nm})$. Automatic spreading using a stirrer plate and a magnetic bar is easier than manual spreading and produces basically the same results in terms of maximum efficiency (Fig. 4). Higher transformation efficiency is achieved when cells are in the stationary phase than as opposed to the exponential growth phase, which can be attributed to the higher number of cells tested under these conditions

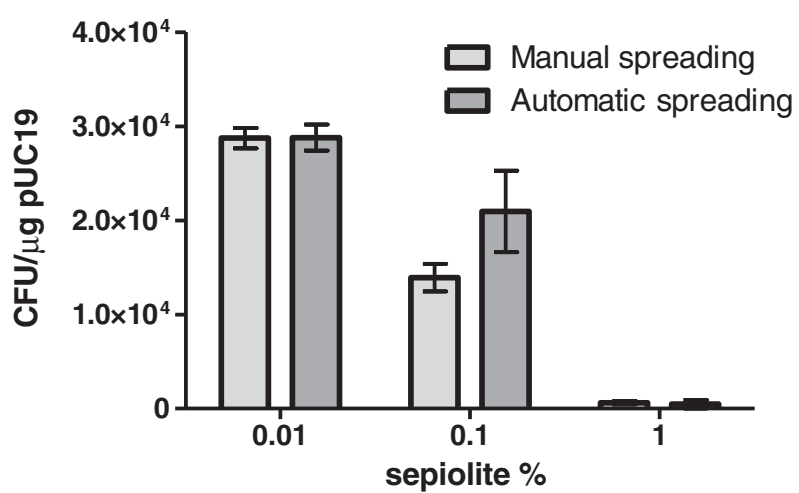

Fig. 4. Manual spreading versus automatic spreading during $30 \mathrm{~s}$ at $\mathrm{OD}_{600}=1.3$ for $E$. coli. 


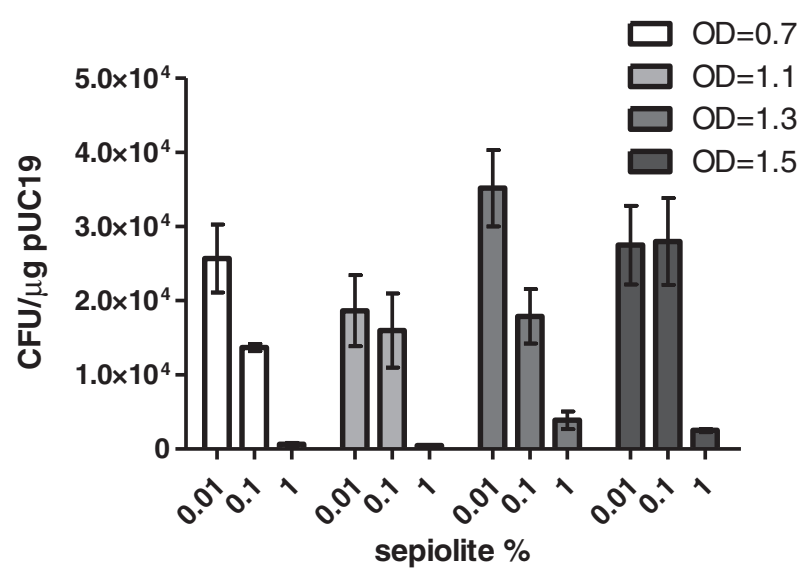

Fig. 5. Sepiolite concentration versus transformation efficiency at different optical densities. The spreading was manually performed during $30 \mathrm{~s}$.

(Fig. 5). In addition, it is likely that along cell growth there are differences in transformation efficiency, caused by the physiological age of cells related to the physical structure of the membrane/cell wall varying with age which facilitates permeation by the nanoneedles. The graph in Fig. 5 is related to cell concentration as well as physiological conditions of the cells. To ascertain that the physiological conditions are a crucial factor in transformation efficiency, the same amount of cells needs to be tested and on these essays only the time of growth is taken into account, since all Petri dishes received the same volume of cells $(100 \mu \mathrm{L})$. Fig. 6 shows the results of the essays performed at $\mathrm{OD}_{600}=$ $0.7,1.1,1.3$ and 1.5 and dilutions or concentrations to $\mathrm{OD}_{600}=0.2,0.7$ and 1.2 were made to ensure that all Petri dishes received the same number of cells for each initial optical density. Here we can see that the physiological conditions of the cells are a crucial factor in transformation efficiency and the highest transformation efficiency attained was at $\mathrm{OD}_{600}=1.2$ from initial $\mathrm{OD}_{600}$ of 1.3 (efficiency $=$ $2.0 \times 10^{4} \mathrm{CFU} / \mu \mathrm{g}$ pUC19), which shows that the age of cells by itself contributes to the success of the procedure.

The influence of spreading times on transformation efficiency for P. putida KT2440 and P. aeruginosa PA01 was studied by Jerónimo Rodríguez-Beltrán et al. For $P$. putida the best spreading time was $30 \mathrm{~s}$ while for $P$. aeruginosa there was no preferred spreading time during $30 \mathrm{~s}, 60 \mathrm{~s}$ and $120 \mathrm{~s}$, which shows that the diversity of cell envelopes can largely influence transformation (Rodríguez-Beltrán et al., 2012). In our case the differences are not significant between 30 and $60 \mathrm{~s}$ for automatic spreading but are considerable between 15 and $120 \mathrm{~s}$, demonstrating an optimum regime for spreading automatically located in the window 30-60 s (Fig. 7). These results led to the conclusion that

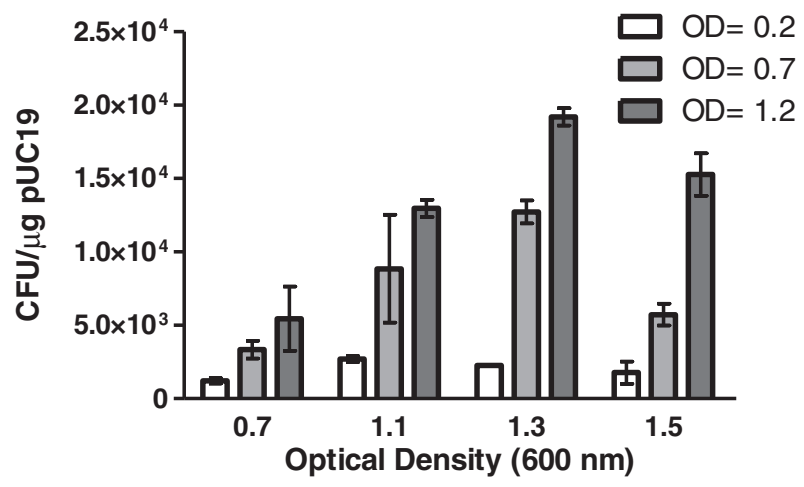

Fig. 6. Optical density versus transformation efficiency. Dilutions or concentrations were performed to $\mathrm{OD}_{600}=0.2,0.7$ and 1.2 to ensure that all Petri dishes received the same number of cells for a certain optical density. The concentration of sepiolite used was $0.01 \%$.
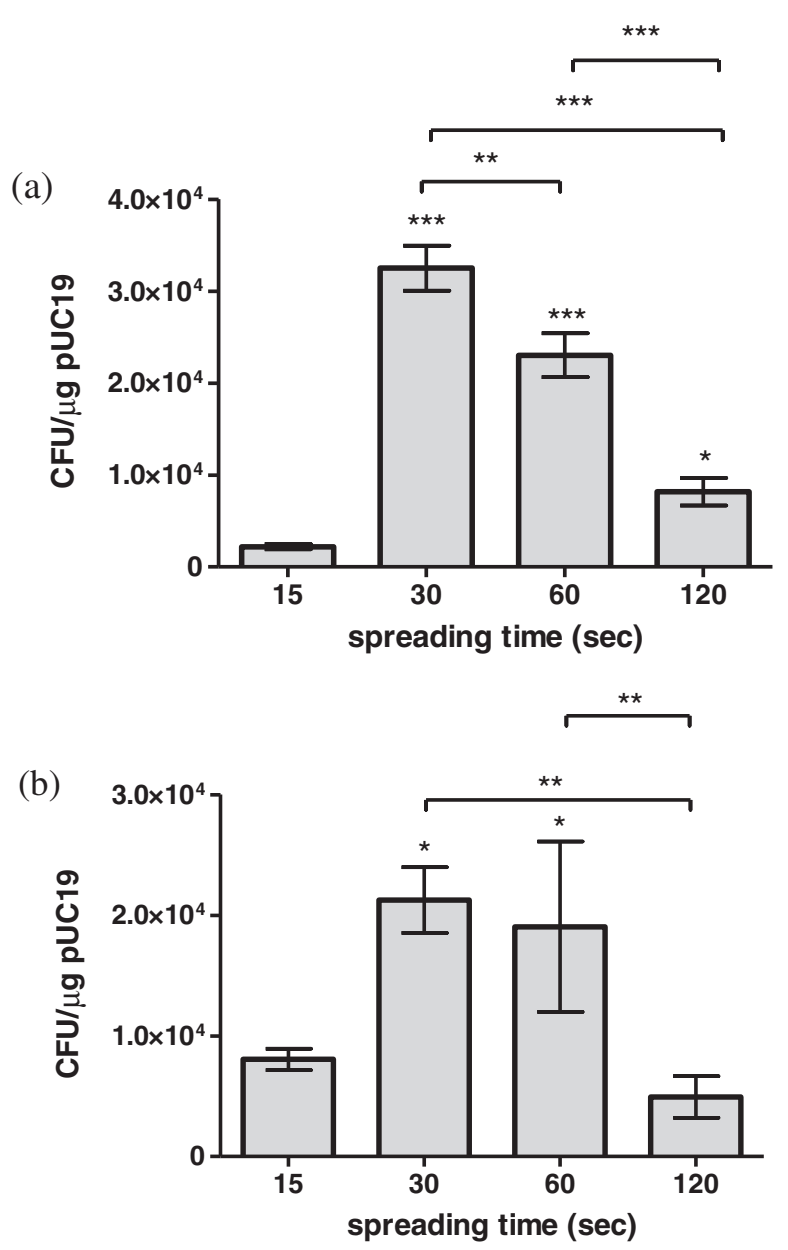

Fig. 7. Manual spreading (a) versus automatic spreading (b) of E. coli-pUC19-sepiolite dispersion. The sepiolite concentration used in both cases was $0.01 \%$ and a cell optical density of $1.3\left(\mathrm{OD}_{600}=1.3\right)$.

an increase in sepiolite concentration and therefore the increase in the number of nano-needles in the dispersion while spreading the E. colipUC19-sepiolite dispersion on top of agar/LB Petri dishes may give rise to cell bursting. Indeed, Yoshida postulated that nano-needle aggregates penetrate the cell membrane when present at high concentration, causing cells to burst as the time of exposure increases (Yoshida and Saeki, 2004a, 2004b; Yoshida, 2007). One should expect that if too

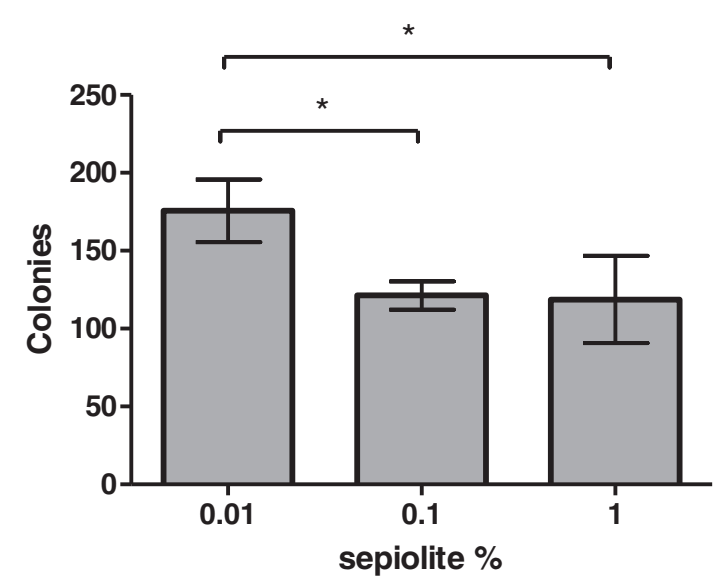

Fig. 8. Cell death evaluation by spreading manually during $30 \mathrm{~s}$ diluted samples of $E$. coli JM109. 


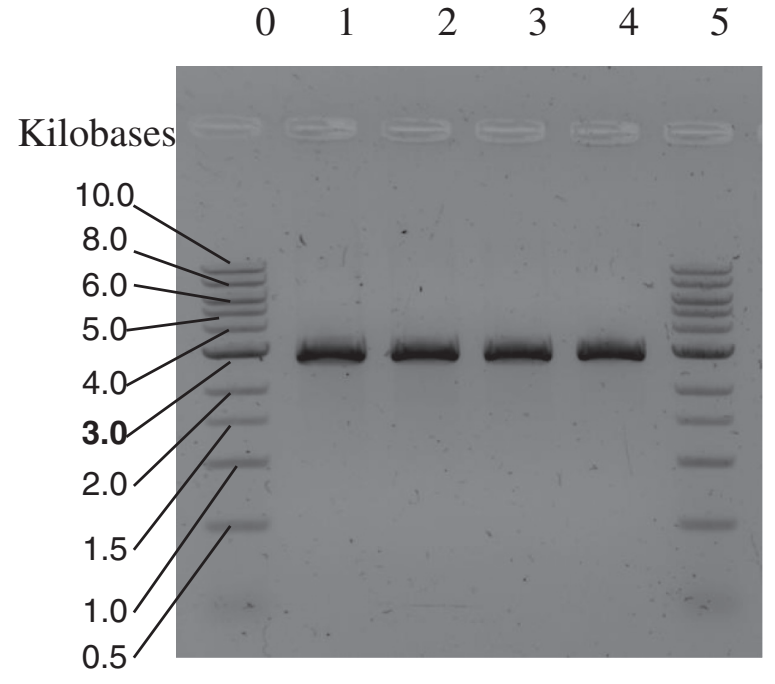

Fig. 9. Agarose gel electrophoresis of pUC19 cut with EcoRV (lines 1 and 2) and HindIII (lines 3 and 4). Lines 0 and 5 are from 1 kb DNA ladder.

many pores are generated in the bacterial wall, the osmotic and mechanical forces may destroy the cells, which leads to cell death and compromises the success of the procedure, as shown in Fig. 8.

Yoshida claims that the mechanism of DNA inoculation through chrysotile asbestos involves the formation of chestnut bur like aggregates (Yoshida and Saeki, 2004a, 2004b). As the liquid phase of E. coli-plasmid-chrysotile suspension is absorbed by the agar mesh during spreading, the concentration of chrysotile increases forming gradually larger aggregates since the chrysotile and bacteria cannot permeate the agar (To and Boyde, 1993) but water, ions and small molecules can move freely through the mesh and diffuse freely throughout the gel. We prepared Petri dishes with sepiolite embedded in the agar mesh and obtained transformants (data not shown) which demonstrates that the chestnut bur formation mechanism is not essential for transformation to occur using sepiolite. The linearized plasmids migrated to just below the $3 \mathrm{~kb}$ ladder (Fig. 9). This, combined with the transformants' resistance to ampicillin and the ability to display blue colonies in the presence of X-gal, confirms that the isolated plasmid is indeed pUC19.

Sepiolite mediated transformation of E. coli JM109 is feasible under the conditions described in this paper, involving modifications of agar and sepiolite concentration, cell density, spreading time and spreading methodology. Even though the transformation efficiency is lower than heat shock or electroporation, each assay results in Petri dishes covered with hundreds of colonies, proving that the method is suitable for most purposes of molecular biology. The main advantages of this method are its low cost, the simplicity of the method that can be accomplished in a few minutes and the use on non-competent cells.

\section{Conflict of interest}

The authors declare that they have no conflict of interest.

\section{Acknowledgments}

This study was supported by the Portuguese Foundation for Science and Technology (FCT) and the European Community fund FEDER, through Program COMPETE, under the scope of the Projects FCOMP-01-
0124-FEDER-007025 (PTDC/AMB/68393/2006), PEst-OE/EQB/LA0023/ 2013, PEST-C/FIS/UI607/2013, RECI/BBB-EBI/0179/2012 (FCOMP-010124-FEDER-027462) and the Projects "BioEnv - Biotechnology and Bioengineering for a sustainable world" and "Matepro-Optimizing Materials and Processes". NORTE-07-0124-FEDER-000048 was co-funded by the Programa Operacional Regional do Norte (ON.2 - O Novo Norte), QREN, FEDER. The authors also acknowledge the fellowship awarded to Gabriel Mendes SFRH/BD/71661/2010 under the scope of the MITPortugal Program.

\section{References}

Bellmann, B., Muhle, H., Ernst, H., 1997. Investigations on health-related properties of two sepiolite samples. Environ. Health Perspect. 105 (Suppl.), 1049-1052. http://dx.doi. org $/ 10.2307 / 3433508$

Huff, J.P., Grant, B.J., Penning, C.A., Sullivan, K.F., 1990. Optimization of routine transformation of Escherichia coli with plasmid DNA. Biotechniques 9, 570-572 (574, 576-7).

Landrigan, P.J., Nicholson, W.J., Suzuki, Y., Ladou, J., 1999. The hazards of chrysotile asbestos: a critical review. Ind. Health 37, 271-280. http://dx.doi.org/10.2486/indhealth. 37.271.

Mera, A., Araki, J., Ohtsuki, T., 2011. Chitin nanowhiskers mediate transformation of Escherichia coli by exogenous plasmid DNA. J. Biotechnol. Biomater. 01, 1-6. http:// dx.doi.org/10.4172/2155-952X.1000114.

Mitsudome, Y., Takahama, M., Hirose, J., Yoshida, N., 2014. The use of nano-sized acicular material, sliding friction, and antisense DNA oligonucleotides to silence bacterial genes. AMB Express 4, 70. http://dx.doi.org/10.1186/s13568-014-0070-7.

Prentice, H.L., 1992. High efficiency transformation of Schizosaccharomyces pombe by electroporation. Nucleic Acids Res. 20, 621. http://dx.doi.org/10.1093/nar/20.3.621.

Rodríguez-Beltrán, J., Elabed, H., Gaddour, K., Blázquez, J., Rodríguez-Rojas, A., 2012. Simple DNA transformation in Pseudomonas based on the Yoshida effect. J. Microbiol. Methods 89, 95-98. http://dx.doi.org/10.1016/j.mimet.2012.02.013.

Rodríguez-Beltrán, J., Rodríguez-Rojas, A., Yubero, E., Blázquez, J., 2013. The animal food supplement sepiolite promotes a direct horizontal transfer of antibiotic resistance plasmids between bacterial species. Antimicrob. Agents Chemother. 57, 2651-2653. http://dx.doi.org/10.1128/AAC.02363-12.

Suzuki, Y., Churge, J., Ono, T., 1972. Phagocytic activity of alveolar epithelial cells in pulmonary asbestosis. Am. J. Pathol. 69, 373-389.

Tan, H., Fu, L., Seno, M., 2010. Optimization of bacterial plasmid transformation using nanomaterials based on the Yoshida effect. Int. J. Mol. Sci. 11, 4961-4972. http://dx. doi.org/10.3390/ijms11124962.

To, K.-Y., Boyde, T.R.C., 1993. Pulsed-field acceleration: the electrophoretic behavior of large spherical particles in agarose gels. Electrophoresis 14, 597-600. http://dx.doi. org/10.1002/elps.1150140194.

Wilharm, G., Lepka, D., Faber, F., Hofmann, J., Kerrinnes, T., Skiebe, E., 2010. A simple and rapid method of bacterial transformation. J. Microbiol. Methods 80, 215-216. http:// dx.doi.org/10.1016/j.mimet.2009.12.002.

Yoshida, N., 2001. Chrysotile asbestos fibers mediate transformation of Escherichia coli by exogenous plasmid DNA. FEMS Microbiol. Lett. 195, 133-137. http://dx.doi.org/10. 1111/j.1574-6968.2001.tb10510.x.

Yoshida, N., 2007. Discovery and application of the Yoshida effect: nano-sized acicular materials enable penetration of bacterial cells by sliding friction force. Recent Pat. Biotechnol. 1, 194-201. http://dx.doi.org/10.2174/187220807782330147.

Yoshida, N., Ide, K., 2008. Plasmid DNA is released from nanosized acicular material surface by low molecular weight oligonucleotides: exogenous plasmid acquisition mechanism for penetration intermediates based on the Yoshida effect. Appl. Microbiol. Biotechnol. 80, 813-821. http://dx.doi.org/10.1007/s00253-008-1637-5.

Yoshida, N., Saeki, Y., 2004a. Chestnut bur-shaped aggregates of chrysotile particles enable inoculation of Escherichia coli cells with plasmid DNA. Appl. Microbiol. Biotechnol. 65, 566-575. http://dx.doi.org/10.1007/s00253-004-1649-8.

Yoshida, N., Saeki, Y., 2004b. Chrysotile fibers penetrate Escherichia coli cell membrane and cause cell bursting by sliding friction force on agar plates. J. Biosci. Bioeng. 97, 162-168. http://dx.doi.org/10.1016/S1389-1723(04)70186-3.

Yoshida, N., Sato, M., 2009. Plasmid uptake by bacteria: a comparison of methods and efficiencies. Appl. Microbiol. Biotechnol. 83, 791-798. http://dx.doi.org/10.1007/ s00253-009-2042-4.

Yoshida, N., Takebe, K., 2006. Quantitative detection of asbestos fiber in gravelly sand using elastic body-exposure method. J. Ind. Microbiol. Biotechnol. 33, 827-833. http://dx.doi.org/10.1007/s10295-006-0125-0.

Yoshida, N., Kodama, K., Nakata, K., Yamashita, M., Miwa, T., 2002. Escherichia coli cells penetrated by chrysotile fibers are transformed to antibiotic resistance by incorporation of exogenous plasmid DNA. Appl. Microbiol. Biotechnol. 60, 461-468. http://dx. doi.org/10.1007/s00253-002-1148-8.

Yoshida, N., Naka, T., Ohta, K., 2004. Mutagenesis of bacteria by fibrous or clay minerals. J. Biol. Sci. 4, 532-536. http://dx.doi.org/10.3923/jbs.2004.532.536. 